\title{
Metallosis in Sequelae of Prosthetic Revision for Ceramic Components Fracture: A Case Report with Clinical Presentation Mimicking Periprosthetic Hip Infection
}

\author{
Stefano Artiaco ${ }^{1}$ Federico Fusini ${ }^{1}$ Kristijan Zoccola ${ }^{1} \quad$ Alessandro Massè $^{1}$ Giulia Colzani ${ }^{2}$ \\ ${ }^{1}$ Department of Orthopaedics and Traumatology, Orthopaedic and \\ Trauma Center, Azienda Ospedaliero Universitaria Città della Salute \\ e della Scienza, Turin, Italy \\ 2 Department of Orthopaedics and Traumatology, Policlinico di \\ Address for correspondence Federico Fusini, MD, Department of \\ Orthopaedics and Traumatology, Orthopaedic and Trauma Center, \\ Azienda Ospedaliero Universitaria Città della Salute e della Scienza, \\ Turin 10126, Italy (e-mail: fusinif@hotmail.com).
} Modena, Azienda Ospedaliera Universitaria, Modena, Italy

Joints 2019;7:215-217.

\author{
Abstract \\ Keywords \\ - metallosis \\ - hip synovitis \\ - periprosthetic hip \\ infection \\ - fracture of ceramic \\ acetabular liner
}

Ceramic on ceramic total hip arthroplasties have been developed and widely used during last decades because of their long-term survival and biomechanical properties. One of the most dangerous complication of these implants is the fracture of the ceramic components. The management of this condition should be carefully planned and the choice of the new implant is crucial. We describe a rare case of severe hip synovitis due to massive metallosis in sequelae of mismanaged prosthetic revision for fracture of the ceramic acetabular liner with an unusual clinical presentation that simulate a periprosthetic infection.

\section{Introduction}

Ceramic component fracture is a well-described complication of ceramic-on-ceramic hip arthroplasty. Even if it is rare, a rapid identification and treatment is essential to avoid severe complication ${ }^{1}$; the persistence of ceramic debris, can lead to more severe systemic complication, due to release of metallic ions. ${ }^{2}$ Symptoms of metal intoxication vary with blood level of metal ions and can lead to patient's death in very severe cases. $^{3}$

We described the unusual clinical presentation, diagnostic, and surgical management of this unique case of hip metallosis presenting as a periprosthetic infection.

\section{Case Presentation}

In March 2014, a 72-year-old Caucasian immune-competent man was referred to our hospital with a suspected diagnosis of periprosthetic hip infection. The patient underwent in 2010, a primary ceramic-on-ceramic total hip arthroplasty, and 3 years after revision surgery was performed for fracture of ceramic liner with a metal-on-polyethylene bearing surface. The patient presented to our observation with persistent hyperthermia $\left(39.0-39.5^{\circ} \mathrm{C}\right)$, local pain, and swelling of the hip and groin. The range of joint motion was slightly limited and little painful. A periprosthetic hip infection was then suspected. An empiric antibiotic therapy was administered for 1 week without improvement.

\section{Preoperative Assessment}

Laboratory examinations revealed increased level of C-reactive protein $(325.2 \mathrm{mg} / \mathrm{L})$, erythrocyte sedimentation rate $79 \mathrm{~mm} / \mathrm{h}$, white blood cell count $(12,000 / \mu \mathrm{L})$, neutrophils count $(8,730 / \mu \mathrm{L})$, and high level of acute-phase inflammatory proteins. Fever persisted high despite antibiotics. Hip radiographs showed a typical feature of severe metallosis, the received

May 1, 2018

accepted

April 18, 2021

published online

June 18, 2021
DOI https://doi.org/

10.1055/s-0041-1730981.

ISSN 2282-4324.

\footnotetext{
(C) 2021. The Author(s).

This is an open access article published by Thieme under the terms of the Creative Commons Attribution-NonDerivative-NonCommercial-License, permitting copying and reproduction so long as the original work is given appropriate credit. Contents may not be used for commercial purposes, or adapted, remixed, transformed or built upon. (https://creativecommons.org/ licenses/by-nc-nd/4.0/) Georg Thieme Verlag KG, Rüdigerstraße 14, 70469 Stuttgart, Germany
} 


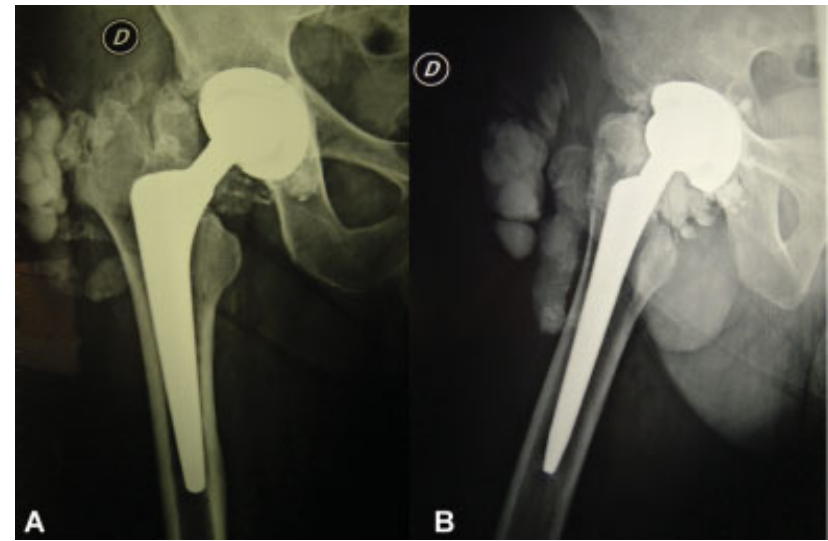

Fig. 1 (A, B) Preoperative radiographs of the right hip showing the bubble sign.

"bubble sign" surrounding the prosthesis (-Fig. 1). ${ }^{4}$ Computed tomography scan of the pelvis revealed a large pseudotumor of the hip $(11 \mathrm{~cm} \times 4 \mathrm{~cm}$; -Fig. 2). Black synovial fluid of $250 \mathrm{cc}$ was aspirated and sent for laboratory evaluation. Microbiological cultures were negative in all five samples, while synovial fluid showed high level of leukocytes (22,000 cell $/ \mathrm{mm}^{3}$ ) and metals ions (titanium, 379,100 $\mu \mathrm{g} / \mathrm{L}$; cobalt, $63 \mu \mathrm{g} / \mathrm{L}$; chrome, 1,379,000 $\mu \mathrm{g} / \mathrm{L}$; molybdenum, $160,400 \mu \mathrm{g} / \mathrm{L}$; vanadium, 17,180 $\mu \mathrm{g} / \mathrm{L}$; and manganese, $265,500 \mu \mathrm{g} / \mathrm{L}$ ). A severe metallosis was than hypothesized and surgical revision was planned.

\section{Surgical Treatment}

A large pseudotumor of the hip was isolated and removed. The soft tissues were black stained and it contained black synovial fluid due to metal debris. After soft tissue debridement and irrigation, the acetabular cup, polyethylene liner, and femoral head were removed. All components showed

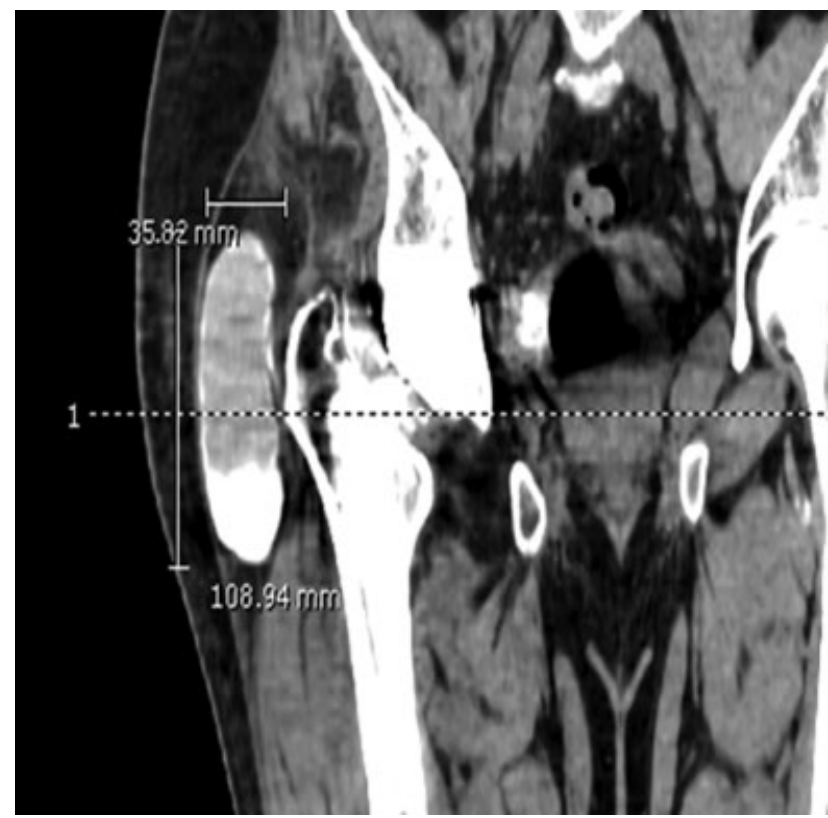

Fig. 2 Preoperative CT scan showing pseudotumor with radiopaque level of synovial fluid. CT, computed tomography.

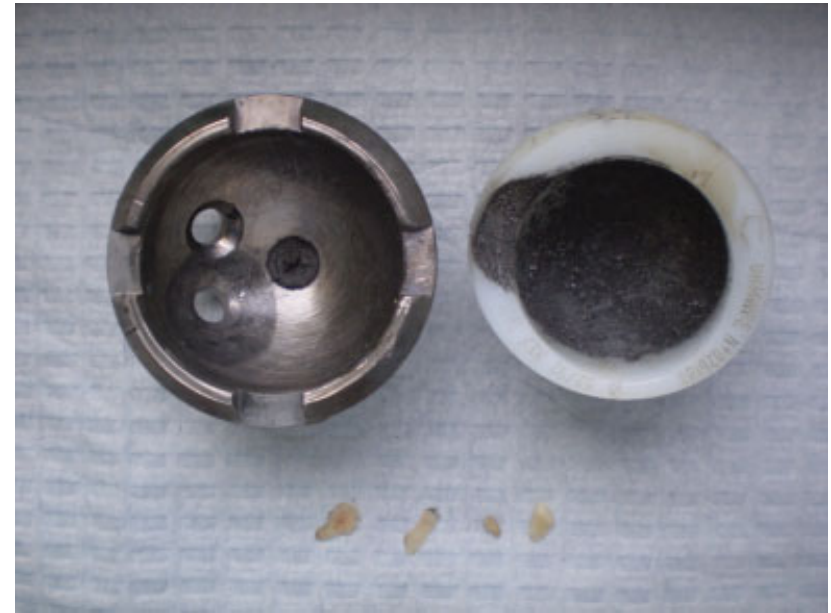

Fig. 3 Removed implant showing ceramic debris and sign of metallosis.

macroscopic wear (-Figs. 3 and $\mathbf{4}$ ). Some ceramic fragments were identified and removed. A ceramic-on-ceramic bearing surface was then restored after residual ceramic fragments removal.

\section{Postoperative Course}

Body temperature returned within normal limits in few days. Hip pain disappeared and the patient followed a standard rehabilitation protocol. Blood and urinary concentrations of metal ions were examined during postoperative course. Metal ions concentrations were followed at the time of surgery (T0), 2 weeks (T1), and 4 weeks (T2) after operation. Blood levels of chrome $(\mathrm{T} 0=5.07 \mu \mathrm{g} / \mathrm{L} ; \mathrm{T} 1=4.62 \mu \mathrm{g} / \mathrm{L}$; and $\mathrm{T} 2=3.6 \mu \mathrm{g} / \mathrm{L})$ and cobalt $(\mathrm{T} 0=0.41 \mu \mathrm{g} / \mathrm{L} ; \mathrm{T} 1=0.62 \mu \mathrm{g} / \mathrm{L}$; and $\mathrm{T} 2=1.02 \mu \mathrm{g} / \mathrm{L}$ ) were slightly increased than normal threshold values. During the first 2 months, the patient reported dysgeusia with a persistent metallic taste that progressively disappeared. In 2 months he returned to daily life activities without limitations.

Regular clinical and radiologic follow-up was observed during subsequent years, with no sign of loosening or wear at 3 years of follow-up with an Harris' hip score of 82 (-Fig. 5). The patient was fully satisfied of clinical results and perceived quality of life.

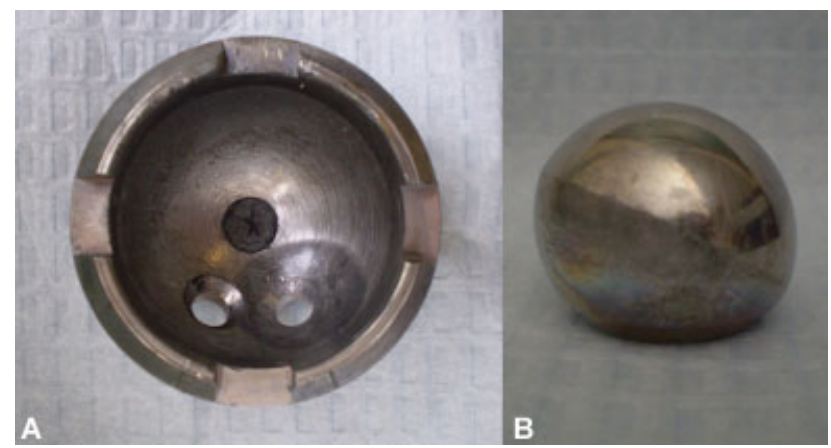

Fig. 4 (A, B) Retrieved acetabular shell and femoral head with macroscopic metal wear. 


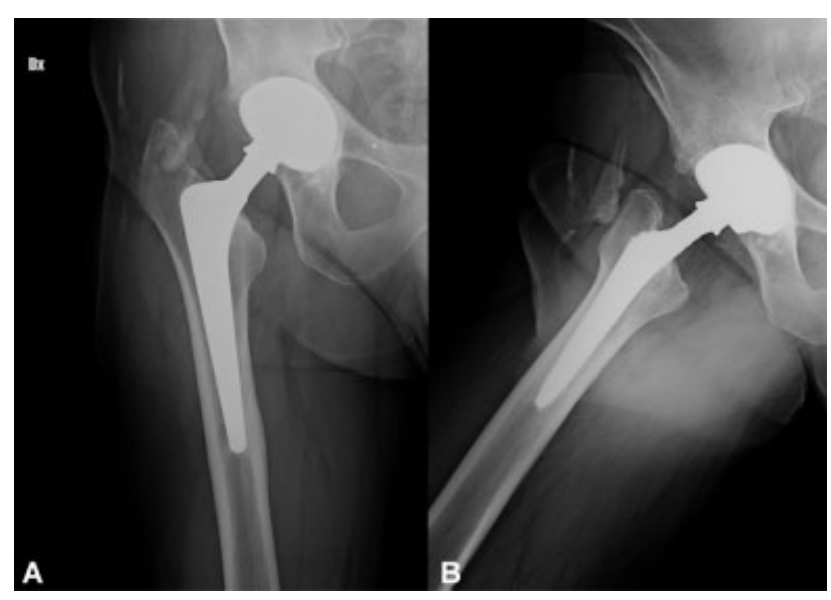

Fig. 5 (A, B) 3-years follow-up radiographs of the right hip with regular appearance.

\section{Discussion}

Fracture of ceramic components may cause catastrophic consequences. $^{5-10}$ Revision surgery should be performed promptly with accurate synoviectomy and joint irrigation to remove ceramic debris and preserve hip implants from abrasive effects. ${ }^{5}$ Some authors reported that revision should be performed with ceramic-on-ceramic implants because early damage and failure of metal and polyethylene may occur because of residual ceramic fragments. ${ }^{6}$

Patients with severe metallosis suffered from serious neurological and cardiac complications which in a case leaded to patient death. ${ }^{11}$

None of reported cases presented with clinical features simulating periprosthetic infection that were observed in our report. Also initial laboratory examinations supported this hypothesis.

Periprosthetic infection associated with component fracture was already reported in literature but in these cases local and systemic symptoms of inflammation were associated with positive cultures. ${ }^{12,13}$ In our case, all symptoms were related to inflammatory response against metal particles and, to the best of our knowledge, this is the first case of severe metallosis simulating a periprosthetic infection.

This report confirms that all patients sustaining a revision hip arthroplasty after fracture of a ceramic component should be carefully controlled with clinical and radiological follow-up and informed about the possibility of future complications related to residual ceramic fragments. A careful investigation must always be performed to correctly and properly reach the correct diagnosis.

\section{Funding \\ None.}

\section{Conflict of Interest}

None declared.

\section{References}

1 Hannouche D, Zaoui A, Zadegan F, Sedel L, Nizard R. Thirty years of experience with alumina-on-alumina bearings in total hip arthroplasty. Int Orthop 2011;35(02):207-213

2 Fehring KA, Fehring TK. Modes of failure in metal-on-metal total hip arthroplasty. Orthop Clin North Am 2015;46(02):185-192

3 Green B, Griffiths E, Almond S. Neuropsychiatric symptoms following metal-on-metal implant failure with cobalt and chromium toxicity. BMC Psychiatry 2017;17(01):33

4 Su EP, Callander PW, Salvati EA. The bubble sign: a new radiographic sign in total hip arthroplasty. J Arthroplasty 2003;18(01): 110-112

5 Traina F, De Fine M, Di Martino A, Faldini C. Fracture of ceramic bearing surfaces following total hip replacement: a systematic review. BioMed Res Int 2013;2013:157247

6 Whittingham-Jones P, Mann B, Coward P, Hart AJ, Skinner JA. Fracture of a ceramic component in total hip replacement. J Bone Joint Surg Br 2012;94(04):570-573

7 Pelclova D, Sklensky M, Janicek P, Lach K. Severe cobalt intoxication following hip replacement revision: clinical features and outcome. Clin Toxicol (Phila) 2012;50(04):262-265

8 Rizzetti MC, Liberini P, Zarattini G, et al. Loss of sight and sound. Could it be the hip? Lancet 2009;373(9668):1052

9 Ikeda T, Takahashi K, Kabata T, Sakagoshi D, Tomita K, Yamada M. Polyneuropathy caused by cobalt-chromium metallosis after total hip replacement. Muscle Nerve 2010;42(01):140-143

10 Oldenburg M, Wegner R, Baur X. Severe cobalt intoxication due to prosthesis wear in repeated total hip arthroplasty. J Arthroplasty 2009;24(05):825.e15-825.e20

11 Zywiel MG, Brandt JM, Overgaard CB, Cheung AC, Turgeon TR, Syed KA. Fatal cardiomyopathy after revision total hip replacement for fracture of a ceramic liner. Bone Joint J 2013;95-B(01): 31-37

12 Donaldson JR, Miles J, Sri-Ram K, Poullis C, Muirhead-Allwood S, Skinner J. The relationship between the presence of metallosis and massive infection in metal-on-metal hip replacements. Hip Int 2010;20(02):242-247

13 Barba T, Wach J, Lustig S, et al; Lyon BJI Study Group. Metallosisassociated prosthetic joint infection. Med Mal Infect 2015;45 $(11,12): 484-487$ 